\title{
Mapping greenhouse plastic wastes in the west region of Portugal
}

\author{
M. Nanna ${ }^{1}$, M.T. Batista 2 ,a, F.J. Baptista ${ }^{2}$, E. Schettini ${ }^{1}$ and G. Vox ${ }^{1}$
}

1Department of Agricultural and Environmental Science, University of Bari, Via Amendola 165/A, 70124 Bari, Italy; ${ }^{2}$ ICAAM - Instituto de Ciências Agrárias e Ambientais Mediterrânicas, Universidade de Évora, Núcleo da Mitra, Ap. 94, 7002-554 Évora, Portugal.

\begin{abstract}
Plastic materials are used in many applications in agriculture, as greenhouse and tunnel covering films, direct coverings, shading and protective nets, irrigation pipes, fertilizers bags, pots and others. In Mediterranean countries, plastic film is the most common greenhouse covering material. Because of direct exposure to solar radiation and wind, greenhouse plastic covers need to be replaced every 6 to 45 months, depending on the material. The huge quantities of plastic waste produced need proper management in order to avoid environmental and economic impacts. The plastic waste is usually recycled by special companies that collect and treat this waste material. The aim of this study was to apply geographical information systems (GIS) and photointerpretation techniques to evaluate the amount of plastic waste produced in one of the most important regions of greenhouse production in Portugal, the west region, specifically the Torres Vedras municipality. The methodology has integrated the characterization of the type of plastic covering material and the cartography of the greenhouse land units. It used Land Use Map 2007, Bing Map images and administrative boundaries to determine the geographical position and the type of greenhouses. For each administrative unit, the frequency and total greenhouse area were calculated. Identification of the type of plastic material was made by photointerpretation and direct interviews at one company that sells material for greenhouses in Torres Vedras. The database created allowed us to determine the amount of plastic used as greenhouse cover materials and to identify the needs for recycling in this area. The geodatabase produced is the first step to monitor plastic waste production in time and space.
\end{abstract}

Keywords: agricultural plastic waste, ArcGIS, land use, waste management

\section{INTRODUCTION}

Greenhouses are built with the purpose of inducing an ideal indoor environment for crops to grow. Generally, they are large structures in which it's possible to stand and to work (Castilla, 2004). The growth of demand for fresh horticultural products has caused a direct increase in global greenhouse area and therefore an increase in agricultural plastic waste (APW) (Picuno, 2014; Scarascia Mugnozza et al., 2016). Regrettably, data for APW are not very widespread. In the EU, the amount of agricultural plastic materials used in 2011 was more than 1.3 million tonnes; their recovery rate was only $46 \%$, and the mechanical recycling rate was about $23 \%$ (Lanorte et al., 2017).

Greenhouses use solar energy to obtain a suitable internal microclimate for the optimization of plant growth conditions. Variation of the spectral wavelength distribution and the amount of solar radiation that passes through the nets and films influences plant growth and productivity, acting on photosynthetic, photomorphogenetic, phototropic and photoperiodic plant responses (Castellano et al., 2008; Schettini et al., 2011; Mistriotis and Castellano, 2012). In fact, the use of plastic in agriculture generates a significant increase in

aE-mail: mtfb@uevora.pt 